\title{
Low cross talk planar multichannel add-drop multiplexer based on sampled Bragg gratings
}

\author{
Hübner, Jörg; Zauner, Dan; Kristensen, Martin
}

Published in:

Technical Digest of the Optical Fiber Communication Conference and Exhibit

Link to article, DOI:

10.1109/OFC.1998.657369

Publication date:

1998

Document Version

Publisher's PDF, also known as Version of record

Link back to DTU Orbit

Citation (APA):

Hübner, J., Zauner, D., \& Kristensen, M. (1998). Low cross talk planar multichannel add-drop multiplexer based on sampled Bragg gratings. In Technical Digest of the Optical Fiber Communication Conference and Exhibit IEEE. https://doi.org/10.1109/OFC.1998.657369

\section{General rights}

Copyright and moral rights for the publications made accessible in the public portal are retained by the authors and/or other copyright owners and it is a condition of accessing publications that users recognise and abide by the legal requirements associated with these rights.

- Users may download and print one copy of any publication from the public portal for the purpose of private study or research.

- You may not further distribute the material or use it for any profit-making activity or commercial gain

- You may freely distribute the URL identifying the publication in the public portal 


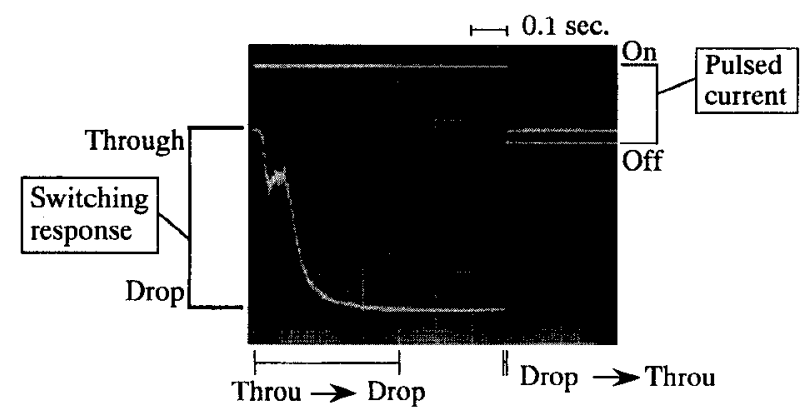

WM57 Fig. 3. Switching response of the device.

driven for a duration of $0.7 \mathrm{sec}$ in the period of $2.0 \mathrm{sec}$. The measurement is done by using a tunable laser of which wavelength is set $0.4 \mathrm{~nm}$ longer than Bragg wavelength without heater operation.

The switching time from "through" to "drop" of a signal, which means the time from the beginning of the heater driving to $90 \%$ down signal power, is about 400 milliseconds. On the other hand, the switching time from "drop" to "through", which means the time from the stopping of the power supply to $90 \%$ up signal restoration, is about 10 milliseconds.

In summary, a novel switchable drop filter has been proposed and demonstrated with photoinduced Bragg grating on a silica-based waveguide with the heater power consumption of $0.124 \mathrm{~W}$ (a driving current is $60 \mathrm{~mA}$ ). Good switching responses were obtained by $0.4-\mathrm{nm}$ shifts of Bragg wavelength.

${ }^{*}$ Advanced Research Center, Hitachi Cable, Limited, Kidamari-cho 3550, Tsuchiura-shi, Ibaraki-ken, 300, Japan.

1. G. Nykolak, M.R.X. de Barros, S. Celaschi, J.T. Jesus, D.S. Shenk, T.A. Strasser, in Optical Fiber Communication Conference, Vol, 6 of 1997 OSA Technical Digest Series (Optical Society of America, Washington, D.C., 1997), paper ThJ2, pp. 281-282.

2. R. Kashyap, Opt. Fiber Technol. 17-34 (1994).

3. H. Uetsuka, K. Tamura, H. Arai, K. Higuchi, S. Kashimura, A. Hongo, in Conference on Lasers and Electro-Optics, Vol. 11 of 1997 OSA Technical Digest Series (Optical Society of America, Washington, D.C., 1997), p. 284.

4. H. Uetsuka, R. Suzuki, K. Tamura, H. Okano, S. Kashimura, A. Hongo, presented at ECOC'97, Edinburgh, UK, September 1997.

5. A. Sugita, K. Jinguji, N. Takato, K. Katoh, M. Kawachi, Trans. IEICE, E76, No. 1, pp. 105-109.

\section{WM58}

\section{Low cross talk planar multichannel add-drop multiplexer based on sampled Bragg gratings}

Jörg Hübner, Dan Zauner, Martin Kristensen, Mikroelektronik Centret, Technical University of Denmark, Building 345 East, DK-2800 Lyngby, Denmark; E-mail: johu@mic.dtu.dk

UV-written sampled gratings have recently been demonstrated in optical fibers and waveguides. ${ }^{1-3}$ The reflection spectrum of a sampled grating consists of a series of peaks, with a spacing inversely proportional to the sampling period. Within a limited frequency range the dispersion may be ignored and the frequency spacing can therefore be assumed constant. This makes sampled gratings useful for wavelength-division multiplexing (WDM) applications. We demonstrate the application of a sampled grating

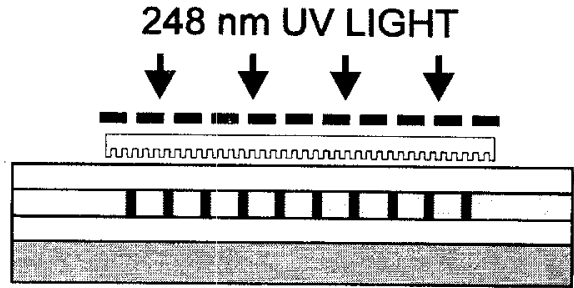

(a)

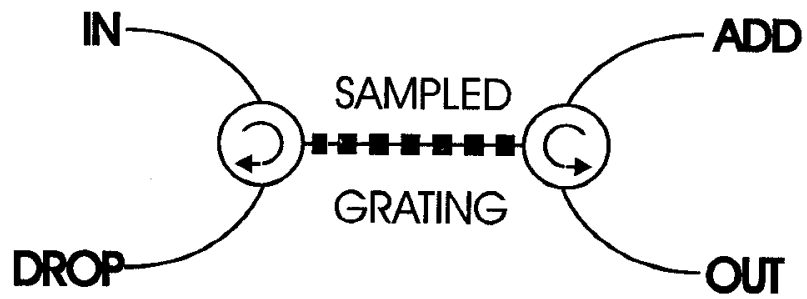

(b)

WM58 Fig. 1. (a) Production process for the sampled grating. We shine 248-nm UV light from an excimer laser through an amplitude mask defining the sampling function on top of a phase mask defining the Bragg grating. (b) The waveguide grating inserted between two circulators with the four ports of the resulting add/drop multiplexer labeled.

for a multi wavelength optical add/drop multiplexer, which drops wavelengths spaced by $400 \mathrm{GHz}$ around a center wavelength of $1557 \mathrm{~nm}$.

Sampled gratings are UV-written using a single exposure through a combination of an amplitude mask and a phasemask as illustrated in Fig. $1(A)$. This allows control of the frequency spacing, the width of the individual peaks and the convolution curve through the period, length and duty cycle of the amplitude mask. ${ }^{3}$ The center wavelength is determined by the phase mask period times the effective refractive index of the waveguide. After the UV-exposure we have annealed the grating at $200^{\circ} \mathrm{C}$ for $30 \mathrm{~min}$ to assure long-term stability.

The reflection and transmission spectra of our sampled grating are illustrated in Fig. 2. The grating has a sampling period of $250 \mu \mathrm{m}$, a length of $38 \mathrm{~mm}$, a duty cycle of $1 / 5$, an index modulation of approximately $1 \cdot 10^{-3}$ and the phase-mask period is $1071 \mathrm{~nm}$. This results in peaks with a reflectivity of more than $99.9 \%$ (30 dB) spaced by $400 \mathrm{GHz}$. Between the peaks the reflectivity drops by more than $20 \mathrm{~dB}$. The insertion loss for the waveguide including the sampled grating is $<4 \mathrm{~dB}$.

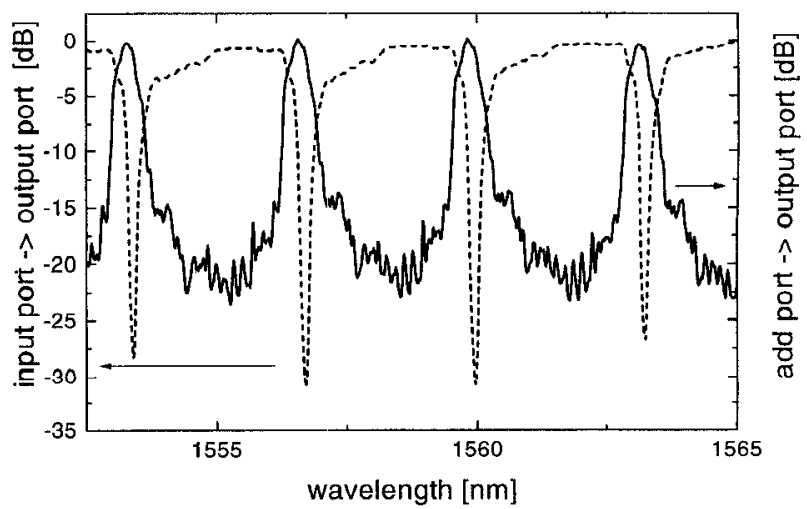

WM58 Fig. 2. Normalized spectral properties of the add/drop multiplexer. The dashed curve is the input to output transmission and the fully drawn curve is the add to output analogous to the input to drop, exhibiting the grating reflection. 
We insert the waveguide with the sampled grating between two 3-port optical circulators and thereby form an add/drop multiplexer as illustrated in Fig. 1(B). The spectral properties of the add/drop multiplexer are determined by the sampled grating and shown in Fig. 2 . The input to output port exhibits the grating transmission spectrum and the input to drop port, analogous to the add to output port, exhibits the grating reflection spectrum. This means that the intraband crosstalk of our device is $-30 \mathrm{~dB}$. When used in a WDM system with $200-\mathrm{GHz}$ channel separation the interband cross talk is $-20 \mathrm{~dB}$, with a $100-\mathrm{GHz}$ channel spacing the interband cross talk is approximately $-17 \mathrm{~dB}$. In a system with $400-\mathrm{GHz}$ channel spacing the grating may instead be used together with only one circulator as an efficient filter for amplified spontaneous emission.

1. B.J. Eggleton, P.A. Krug, L. Poladian, F. Ouellette, Electron. Lett. 30, 1620 (1994).

2. M. Ibsen, B.J. Eggleton, M.G. Sceats, F. Ouellette, Electron. Lett. 31, 37 (1995).

3. M. Ibsen, J. Hübner, J.E. Pedersen, R. Kromann, L.-U.A. Andersen, M. Kristensen, Electron. Lett. 32, 2233 (1996).

\section{WM59}

\section{Characterization of elliptic core fiber acousto-optic tunable filters operated in the single mode and the multi-mode range}

K. Oh, Y.W. Park, K.H. Hwang, S.R. Han, H.S. Seo, G.H. Song, Y. Chung, U.C. Paek, S.H. Yun,* H.S. Kim,* B.Y. Kim,* Y.W. Koh,** Department of Information and Communications, Kwangju Institute of Science and Technology, 572 Sangam-dong Kwangsan-ku, Kwangju 506-712, Korea; E-mail: koh@eunhasu.kjist.ac.kr

All-fiber acousto-optic tunable filters (AOTF) are based on the acousticwave-assisted phase matching of the guided fundamental mode to the cladding modes ${ }^{1}$ and the guided higher modes. ${ }^{2}$ Resonant mode coupling takes place when the acoustic wavelength is matched to the beat length between the coupled modes, $L_{B}=2 \pi /\left(\beta_{1}-\beta_{2}\right)$ where $\beta_{1}$ and $\beta_{2}$ are modal propagation constants. In this work, we characterize modal properties of elliptical-core fibers very accurately by means of the acousto-optic mode coupling and show that with appropriate design parameters an elliptical-core fiber can be used for broadband acousto-

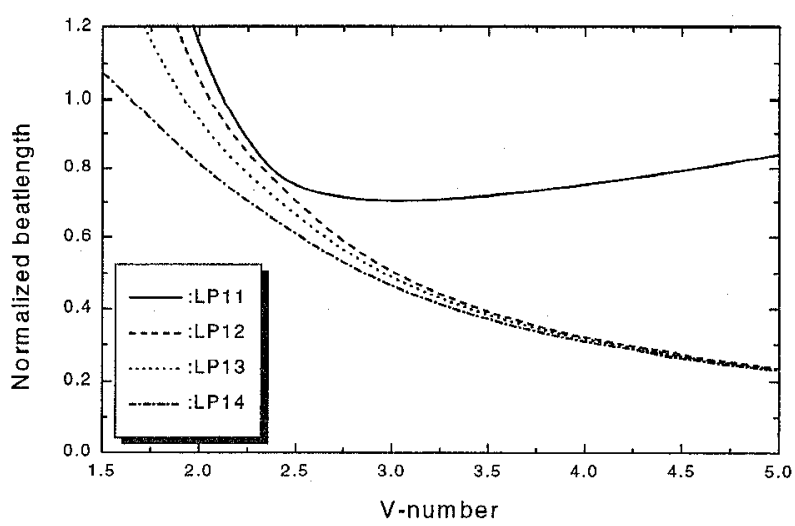

WM59 Fig. 1. Theoretical analysis of the normalized beat length for the coupling of the $\mathrm{LP}_{01}$ mode and the antisymmetric high-order modes. optic tunable filters operated both in 1.5 and $1.3 \mu \mathrm{m}$ communication windows.

In the case of elliptic-core fibers, a large splitting in $\beta$ is introduced in the antisymmetric higher-order modes with respect to their lobe orientations. ${ }^{3}$ In Fig. 1, we plot the normalized beat length, $F(V)=L_{B}$ $\Delta^{1 / 2} / 2^{3 / 2} \pi \mathrm{a}_{\text {eff }}^{1 / 2}$, between the $\mathrm{LP}_{01}$ mode and four antisymmetric modes, the $L P_{11 \text {,even }}, L P_{11 \text {,odd }}, L P_{12}$, and $L P_{13}$ modes, of an elliptical-core fiber (ellipticity of $1-a_{y} / a_{x}=0.25$ ) used in the experiment described below. Here, $V=(2 \pi / \lambda) a_{\text {eff }} n_{\text {eff }}(2 \Delta)^{1 / 2}$ is the normalized frequency, $\Delta$ the normalized index difference between the core and cladding, $n_{\text {eff }}$ the effective index of the fiber, and $a_{\text {eff }}=\left(a_{x} a_{y}\right)^{1 / 2}$ the effective core radius

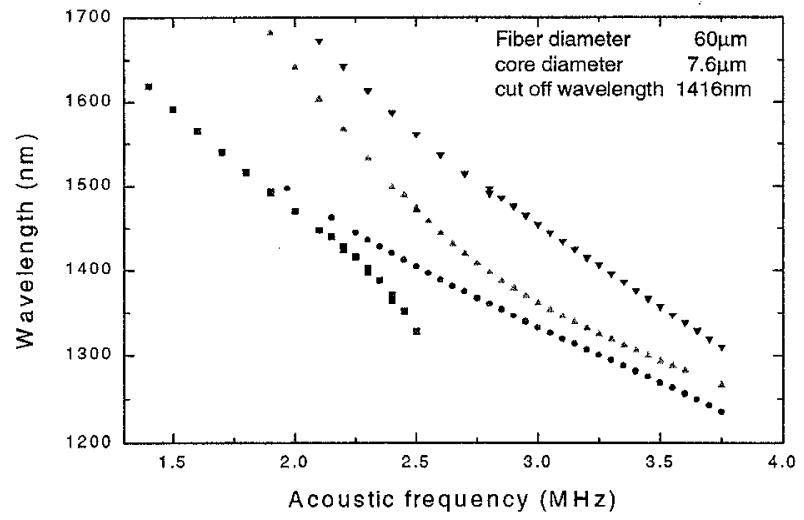

(a)

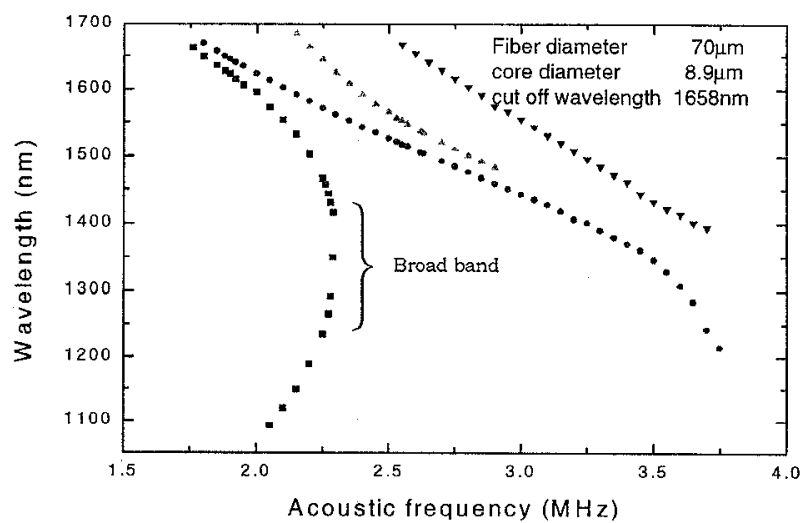

(b)

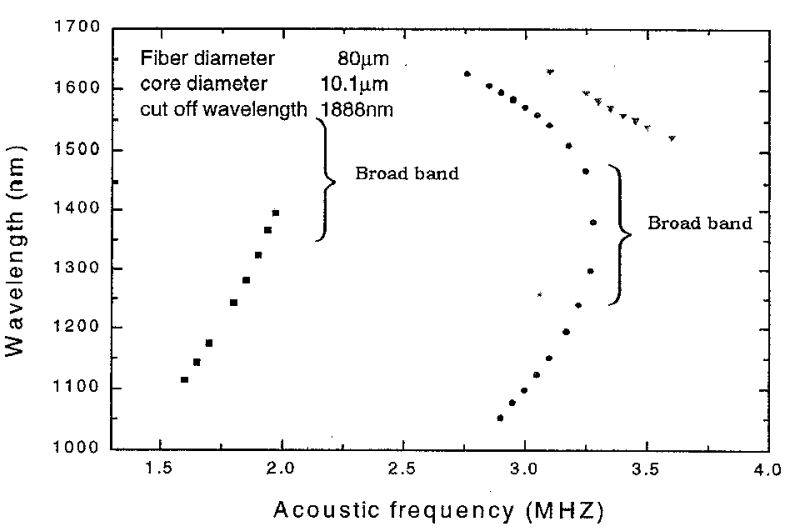

(c)

WM59 Fig. 2. The center wavelengths of filters as a function of the acoustic frequency. Here $\mathrm{d}$ and $\lambda_{c}$ are the fiber diameter and cut-off wavelength, respectively. $\mathrm{d}=$ (a) $62 \mu \mathrm{m}$, (b) $70 \mu \mathrm{m}$, (c) $80 \mu \mathrm{m}$. 